\title{
Flooding: abiotic constraint limiting vegetable productivity
}

\begin{abstract}
Flooding is a major environmental stress that severely limits crop productivity and it has become a major problem worldwide. More than one third of the world's irrigated area suffers due to flooding, frequently or otherwise. It may result due to heavy rainfall, faulty irrigation, unleveled land, poor drainage or heavy soil texture. Various morpho-physiological, biochemical and anatomical changes induced in root system during flooding, for example reduction in the shoot-root relative growth, Formation of thicker adventitious roots or air roots, arenchyma formation and cuboidal packing of cells enhances the longitudinal transport of gases, the major shift occurs in the carbohydrate metabolism of the plants, which move towards lactate and ethanolic fermentation to provide the required ATP. Oxygen diffusion is 10,000 times slower in waterlogged soil as compared to air. Continued flooded conditions lead to lack of oxygen in the soil, restricting respiration of the growing roots and other living organisms. Soil chemical properties also change when anaerobic conditions persist for several days. This is followed by loss of chlorophyll of the lower leaves, arrest of crop growth and proliferation of surface root growth with the retreat of water level. Plant transpiration is affected under anaerobic conditions and extended water logging results in root death due to inadequate oxygen supply.
\end{abstract}

Keywords: arenchyma, flooding, growth, respiration, stress
Volume I Issue 3 - 2014

\author{
Pradeep Kumar Patel,' Amit Kumar \\ Singh,' Niraj Tripathi, ${ }^{3}$ Dinesh Yadav, ${ }^{2}$ A \\ Hemantaranjan ${ }^{2}$ \\ 'Indian Institute of Vegetable Research, India \\ ${ }^{2}$ Department of Plant Physiology, Banaras Hindu University, India \\ Biotechnology Centre, Jawaharlal Nehru Krishi Vishwa Vidyalaya \\ (JNKVV), India
}

\begin{abstract}
Correspondence: A Hemantaranjan, Department of Plant Physiology, Banaras Hindu University, Institute of Agricultural Sciences, Varanasi-221005, Uttar Pradesh, India, Tel +0542-
\end{abstract} 6702939, Email hemantaranjan@gmail.com

Received: June 21, 2014 | Published: July 23, 2014
Abbreviations: FAO, food and agriculture organization; NPQ, non-photochemical quenching; Mn, manganese; $\mathrm{N}$, nitrogen; PS, photosystem; ROS, reactive oxygen species; LDH, lactated dehydrogenase; ANPs, anaerobic polypeptides; PGA, phosphoglycerate; ACC, aminocyclopropane carboxylic acid; BAP, benzylaminopurine; QTL, quantitative trait loci; CIM, composite interval mapping

\section{Introduction}

Soil water is a critical factor of plant distribution in the world, and even usually causes environmental stress such as drought or waterlogging to affect plant characteristics. In tropical and subtropical regions, excessive rainfall is the major constraint for crop production. Flooding is an environmental stress that severely limits crop growth and productivity. It has become a major problem in some parts of the world. Flooding is common in rain-fed ecosystems, especially in soils with poor drainage. Waterlogging affects $10 \%$ of the global land area and is one of the most important constraints imposed on agricultural crop production. The yield penalty resulting from waterlogging may vary between $15 \%$ and $80 \%$, depending on the species, soil type and duration of the stress. Flooding can seriously reduce yield among the stresses considered by the Food and Agriculture Organization (FAO) and the International Institute for Applied Statistical Research in their estimates of global arable land area and global productivity. Flooding can result in yield reduction of up to $10 \%$ and $40 \%$ in severe cases. ${ }^{1}$ Waterlogging often occurs in many regions around the world because of excessive rainfall or poor drainage. By reason of hypoxia in the plant rhizosphere, waterlogging can severely impair the performance of terrestrial plants, whose morphological and physiological responses are prone to activation. The leaf is also very receptive to waterlogging; respiration changes in the leaf, leaf chlorophyll content and photosynthetic assimilation have been detected during a waterlogging period. In particular, chlorophyll fluorescence characteristics are usually influenced under waterlogging conditions. A reduction in the maximum quantum yield of photosystem (PS) II $(\mathrm{Fv} / \mathrm{Fm})$ after the onset of waterlogging has been reported in some plant species. ${ }^{2}$ This decline may be induced by the lowered stomatal conductance (gs), altered hormonal status and disordered mineral nutrient uptake. Furthermore, these factors can also change other indices of chlorophyll fluorescence, such as, electron transport, nonphotochemical quenching (NPQ) and photochemical quenching in environmental stress. After waterlogging, recovery is very critical to each plant species, especially to cultivars. An ideal waterloggingtolerant species not only survives waterlogging, but also rapidly recovers after it. The recovering capabilities of some plant species are strikingly different from one another after waterlogging drainage. Some waterlogged species can rapidly recover to the control level after waterlogging, and others take a very long time. Vegetables are the best resource for overcoming micronutrient deficiencies and provide smallholder farmers with much higher income and more jobs per hectare than staple crops. ${ }^{3}$ The worldwide production of vegetables has doubled over the past quarter century and the value of global trade in vegetables now exceeds that of cereals. Vegetables are generally sensitive to environmental extremes, and thus excessive soil moisture or flooding is the major causes of low yields in the tropics and will be further magnified by climate change. Meager information is available in respect to the flooding stress in vegetable crops. Therefore it is need to see the sights the effect of waterlogging stress on vegetable crops.

\section{Physico-chemical events during flooding}

\section{Change rhizosphere chemistry}

Excess water causes a sharp decrease in soil redox potential, 
resulting in very significant changes to the soil elemental profile. As soon as the free oxygen is depleted, nitrate is used by soil microorganisms as an alternative electron acceptor in respiration. Manganese (Mn) oxides are the next electron acceptors, followed by iron and sulphate. This results in a dramatic build up in the amount of soluble iron $\left(\mathrm{Fe}^{2+}\right)$ and $\mathrm{Mn}^{2+}$ in the soil solution, often to above toxic levels. ${ }^{4}$ It should be also kept in mind that the solubility of potentially toxic metal cations is strongly dependent on soil $\mathrm{pH}$ and the toxicity of some of these elements may increase even further in some soil types (such as $\mathrm{Mn}^{2+}$ in acid soils). It should be noted in this context that waterlogging usually results in a drift towards neutrality, thus causing changes in nutrient solubility. As waterlogging stress progresses, a further decrease in redox potential results in the reduction of sulphate to hydrogen sulphide. Finally, methane formation, from the reduction of carbon dioxide and certain organic acids, is initiated at redox potentials of $200 \mathrm{mV}$ (at pH7). Impeded gas exchange during soil waterlogging also leads to high partial pressure of $\mathrm{CO}_{2}\left(\mathrm{pCO}_{2}\right)$ in the root zone, with some serious consequences for root growth and metabolism. High root zone $\left(\mathrm{pCO}_{2}\right.$ will lead to high concentrations of $\left.\mathrm{HCO}_{3}\right)$ in the cytoplasm, with implications for metabolic regulatory systems. Rice and other wetland plants can tolerate high $\mathrm{pCO}_{2}$ but non wetland species suffer rapid damage. Also, in waterlogged soils, the main form of plant-available nitrogen $(\mathrm{N})$ is $\mathrm{NH}_{4}^{+}$, and plant adaptations to $\mathrm{NH}_{4}+$ Vs $\mathrm{NO}_{3}$ - nutrition may be important under prolonged waterlogging. Some wetland species are particularly efficient at absorbing $\mathrm{NO}_{3}-$ , possibly to scavenge $\mathrm{NO}_{3}$ - formed in the rhizosphere by nitrifiers depending on $\mathrm{O}_{2}$ released from roots. Numerous volatile (short-chain) fatty acids and phenolics also accumulate in soils during prolonged waterlogging.

Soil flooding usually influences plant growth in a negative way as nutritional point of view. Waterlogging reduces the endogenous levels of nutrient in different parts of plants. ${ }^{5}$ Oxygen deficiency in the root zone causes a marked decline in the selectivity of $\mathrm{K}^{+} / \mathrm{Na}^{+}$uptake and impedes the transport of $\mathrm{K}^{+}$to the shoots. The early senescence of leaves and the retarded growth of shoots in flooded plants are caused by the inhibition of nitrogen $(\mathrm{N})$ uptake and the consequent redistribution of nitrogen within the shoot. Moreover, the hampered efficiency of photosystem (PS) II is attributed to the deficiencies of N, $\mathrm{P}, \mathrm{K}, \mathrm{Mg}$ and $\mathrm{Ca}$. It is evident from the literature that adverse effects of waterlogging are not due to the toxic levels of $\mathrm{Na}$ and $\mathrm{Fe}$ but reduced concentrations of $\mathrm{N}, \mathrm{P}, \mathrm{K}, \mathrm{Ca}$ and $\mathrm{Mg}$ are the major contributors. ${ }^{2}$

\section{Plant metabolism and energetic alteration}

Aerobic respiration by roots and microorganisms reduces the oxygen concentration in the rhizosphere leading to hypoxia/anoxia. Therefore, aerobic respiration gets hampered, oxidative phosphorylation is negligible and plants shift their metabolism to anaerobic mode. One of the most important consequences of energy limitation under anoxia is altered redox state of the cell. Due to unavailability of oxygen, the intermediate electron carriers in electron transport chain become reduced, affecting redox active metabolic reactions. Therefore, cells require maintaining their redox characteristics, i.e. $\mathrm{NADH} / \mathrm{NAD}^{+}$ ratio unaffected under waterlogging. ${ }^{6}$ Saturated electron transport components, the highly reduced intracellular environment and low energy supply are the factors favorable for reactive oxygen species (ROS) generation. The consequences of ROS formation depend on the intensity of the stress as well as on the physicochemical conditions in the cell (i.e. antioxidant status, redox state and $\mathrm{pH}$. Generation of ROS under stress condition may cause lipid peroxidation, enzyme inactivation, and oxidative damage to DNA. ${ }^{7}$ Elevated cytoplasmic $\mathrm{Ca}^{2+}$ concentration, cytoplasmic acidification and change in cell membrane permeability are the most common features observed under waterlogged conditions. Inhibition of mitochondrial respiration, ATP synthesis and photosynthesis. Anaerobic metabolism (ethanolic and lactic fermentation) ANPs synthesis. Species tolerant to soil waterlogging are generally considered those able to maintain their energy level via fermentation. In addition to keep on appropriate energy level maintenance of cytosolic $\mathrm{pH}$ is critical. When hypoxia or anoxia occurs the $\mathrm{pH}$ of the cytoplasm shows an early decrease that is attributed to an initial production of lactic acid by fermentation. According to the "Davis- Roberts $\mathrm{pH}$-state theory" the decline in $\mathrm{pH}$ permits the switch from lactate to ethanol fermentation by inhibition of lactated dehydrogenase (LDH) and activation of $\mathrm{ADH} .{ }^{8}$ Because acidosis increases cell necrosis, the switch taking place maintains $\mathrm{pH}$ at approximately 6.8 thus allowing cell survival.

\section{Alterations in physiological mechanisms}

One of the earliest responses to soil flooding is a reduction in stomatal conductance, inhibition of stomatal aperture. Low $\mathrm{O}_{2}$ level may also reduced hydraulic conductivity $(L p)$ consequently to decreased root permeability. The decrease in $L p$ may linked to aquaporins gating by cytosolic $\mathrm{pH}^{9}$ and also limit water uptake thus in term of leading internal water deficit. ${ }^{10,11} \mathrm{O}_{2}$ deficiency generally induced a rapid reduction in the rate of photosynthesis which is generally considered as results of reduced stomatal aperture, decrease in leaf chlorophyll contents, early leaf senescence and a reduction in leaf area may also contribute to inhibition of photosynthesis in later stage. Indeed waterlogged soil tends to reduce the translocation of photosynthesis product from 'source' leaf to 'sink' root ${ }^{12}$ as a results the maintenance of photosynthetic activity and accumulation of soluble sugar to roots is clearly an important adaptation to flooding. In vegetables waterlogging caused a marked reduction in stomata conductance of bitter melon. This reduction in gs resulted in increased leaf water potential. ${ }^{13}$ In contrast, Ashraf et al. ${ }^{14}$ found no significant correlation between stomata conductance and water potential of okra plants under waterlogged conditions.

\section{Root respiratory capacity}

Reduction of root respiration is one of the earliest responses of plants under anoxia, regardless of whether the plants are floodingtolerant or intolerant. ${ }^{15-22}$ The respiratory capacity of bitter melon fell to $28 \%$ that of the non-flooded bitter melon level after 5 days of flooding. ${ }^{20}$ This phenomenon may be valuable for survival and may help flooded roots scavenge any oxygen available around the roots. A high oxygen consumption rate in root tips is associated with respiration, which is required for related metabolic activities, such as generation of ATP. Under flooded conditions, plant roots are in a state of hypoxia, their metabolic activity is inhibited and ATP production decreased. ${ }^{23}$ The decreased ATP production restricts the supply of energy for root growth, thus reducing vegetative growth.

\section{Anaerobic metabolism of roots}

Plants also respond to anoxia by altering the pattern of protein synthesis. The proteins which are synthesized as a specific response to anaerobiosis are called the anaerobic polypeptides (ANPs). ${ }^{24}$ Several ANPs have been characterized by means of protein chemistry and the molecular approach. All the characterized polypeptides are glycolytic enzymes. ${ }^{25,26}$ Among the ANPs, ADH is predominant and has been 
extensively studied. ${ }^{24}$ Newly synthesized ADH isozymes emerge during flooding in many plants ${ }^{19,20,27}$ and with different biochemical properties. The reaction catalyzed by the enzyme is, however, not the rate-limiting step in ethanolic fermentation and the regulatory significance of the massive induction of ADH remains unclear. ${ }^{28}$

\section{Photosynthetic capacity of mesophyll cells}

The activation level of Rubisco in flooded bitter melon increased above the control value after 1 day of flooding and subsequently declined to a lower level. ${ }^{13}$ Changes in the level of activation of Rubisco reflect the level of carbamylation of Rubisco, ${ }^{29}$ which in turn is regulated by $C i$ and light intensity. ${ }^{30}$ In general, the activation level of Rubisco generally declines as $C i$ increases. ${ }^{30-32}$ The relationship between Rubisco activation and the internal $\mathrm{CO}_{2}$ concentration of leaves has been extensively discussed by Liao et al. ${ }^{13}$ The activation level of Rubisco was observed to be $92 \%$ at a $\mathrm{Ci}$ level of $240 \mu$ bars in control plants; this increased to $103 \%$ as $C i$ increased to $251 \mu$ bars and then declined as $\mathrm{Ci}$ further increased in flooded plants. When $\mathrm{Ci}$ was raised to $355 \mu \mathrm{bars}$, the activation level of Rubisco fell to $79 \%$ of the control level. ${ }^{13}$ The effect of elevated $C i$ on the activation level of Rubisco agrees well with the ambient $\mathrm{CO}_{2}$ enrichment reported by Sage et al., ${ }^{30} \&$ von Caemmerer and Edmondson. ${ }^{31}$ Under elevated $C i$, the pool size of RuBP was found to decline and the level of phosphoglycerate (PGA) to increase in three different plant systems. ${ }^{31-33}$ Sage $^{34}$ suggested that excessive consumption of RuBP may switch off the active site of Rubisco, thus maintaining a balance between RuBP consumption and its regeneration, and regulating the activation of Rubisco. The bitter melon studies indicate that $\mathrm{Ci}$ elevation may affect Rubisco regulation in a similar manner..$^{13}$ It has been established that the carbamylation/decarbamylation equilibrium of Rubisco involves reversible active enzyme- $\mathrm{CO}_{2}-\mathrm{Mg}^{2+}$ complex formation. Formation of this complex is $\mathrm{pH}$ dependent and has been observed in leaf homogenates ${ }^{35}$ and isolated chloroplasts. ${ }^{36}$ At a concentration of $0.2 \mathrm{M} \mathrm{Mg}^{2+}$, optimal Rubisco activity was found to be between $\mathrm{pH} 8.5$ to 10 , whereas $90 \%$ of the enzyme activity was lost when the $\mathrm{pH}$ was lowered to 7.0. ${ }^{35}$ Andrews et al., ${ }^{37}$ postulated that a high level of $\mathrm{CO}_{2}$ favors over production of PGA and leads to acidification of the stromal phase, thus reducing the carbamylation level of Rubisco. In bitter melon seedlings, Rubisco activity was found to average $59 \%$ of the control value on the $7^{\text {th }}$ day after flooding. ${ }^{13}$ In as much as Rubisco catalyzes the initial reaction during the assimilation of atmospheric $\mathrm{CO}_{2},{ }^{37}$ the activation level of Rubisco should be positively correlated with the rate of photosynthesis. The leaf soluble protein of flooded bitter melon was found to decline slowly and to reach an average of $75 \%$ of the control level on the $7^{\text {th }}$ day of flooding, but the Rubisco content was reduced significantly. Based on the positive correlation between Rubisco activity and Rubisco content $\left(\mathrm{R}^{2}=0.89\right)$ as well as on the decreased activation level of Rubisco, it can be inferred that a reduced quantity of Rubisco protein as well as reduced activity of existing enzymes may cause Rubisco activity to decline during flooding. Furthermore, it was reported that phloem transport of photosynthates was blocked ${ }^{38}$ and that the demand for sucrose loading was lowered. This may lead to an accumulation of starch in the chloroplasts. ${ }^{13,39}$ It can, thus, be suggested that feedback inhibition of starch accumulation may result in a reduction of CER in flooded plants. The many physiological responses observed indicate that both stomatal and metabolic factors are responsible for the reduction of CER during flooding stress.

Leaf gas exchange parameters have been used to study the photosynthetic capacity of plants during flooding. Except in some flood-tolerant plants that have developed adaptive mechanisms so as to maintain better photosynthetic capacity, ${ }^{40}$ flooding causes a significant decrease in the capacity for leaf gas exchange in most flooding-intolerant plants. Examples are Lycopersicon esculentum, ${ }^{41}$ Pisum sativum, ${ }^{42}$ Studies showed that in pea plants that were subjected to soil flooding, the foliar ABA content increased, accompanied by closure of stomata's. ${ }^{43,44}$ Similar results have been observed in tomato ${ }^{45}$ and apples. ${ }^{46}$ Furthermore, a decrease of stomatal conductance was found to be correlated with an increase of leaf water potential in flooded bitter melon. ${ }^{13}$ Those observations indicate that marked stomatal closure results in an increase in leaf water potential. It can be hypothesized that stomatal closure slows the transpiration rate, thus preventing leaf dehydration.$^{47}$ In control and flooded plants, stomatal conductance was shown to be correlated with $\mathrm{CER}\left(\mathrm{CO}_{2}\right.$ exchange rate). ${ }^{48-50}$ These results imply that stomatal aperture is a limiting factor for CER.

The internal $\mathrm{CO}_{2}$ concentration $(\mathrm{C} i)$ of leaves was found to increase linearly with the duration of flooding, despite a reduction of stomatal conductance. The ambient $\mathrm{CO}_{2}$ concentration was estimated to average $350 \mu$ bars, but less than $300 \mu$ bars were detectable in the leaf intercellular space in leaves of bitter melon plants that had not been subjected to flooding. The $C i$ was found to be $380 \mu$ bars in flooded bitter melon on the $6^{\text {th }}$ day of flooding. ${ }^{13}$ These data suggest that factors such as

\section{i. Reduced photosynthetic capacity}

ii. A respiratory $\mathrm{CO}_{2}$ evolution rate exceeding the $\mathrm{CO}_{2}$ fixation rate iii. Increased stomatal resistance may be involved in $\mathrm{Ci}$ elevation.

It was found that respiration of leaves increased significantly during flooding. ${ }^{13}$ Flooding has been reported to cause stomatal closure directly, without affecting the photosynthetic capacity, in V. ashei. ${ }^{51,52}$ thus decreasing $\mathrm{Ci}$. It has been suggested that the stomatal aperture regulates the decline of CER. However, in flooded bitter melon seedlings, $\mathrm{Ci}$ was observed to increase. ${ }^{13}$ Other plants, in which $C i$ was found to remain unchanged with flooding, are C. illinoensis, ${ }^{49}$ C. sinensis grafted onto C. jamthiri and C. aurantium rootstocks ${ }^{50}$ and bitter melon grafted onto luffa rootstocks. ${ }^{48}$ These observations suggest that stomatal aperture is not the only limiting factor for CER but is partly responsible for the decrease in the photosynthetic capacity of mesophyll tissue.

The activation level of Rubisco in flooded bitter melon increased above the control value after 1 day of flooding and subsequently declined to a lower level. ${ }^{13}$ Changes in the level of activation of Rubisco reflect the level of carbamylation of Rubisco, ${ }^{29}$ which in turn is regulated by $\mathrm{Ci}$ and light intensity. ${ }^{30}$ In bitter melon seedlings, Rubisco activity was found to average $59 \%$ of the control value on the 7 th day after flooding. ${ }^{13}$ In as much as Rubisco catalyzes the initial reaction during the assimilation of atmospheric $\mathrm{CO}_{2},{ }^{53}$ the activation level of Rubisco should be positively correlated with the rate of photosynthesis. The leaf soluble protein of flooded bitter melon was found to decline slowly and to reach an average of $75 \%$ of the control level on the $7^{\text {th }}$ day of flooding, but the Rubisco content was reduced significantly.

Based on the positive correlation between Rubisco activity and Rubisco content $\left(\mathrm{R}^{2}=0.89\right)$ as well as on the decreased activation level of Rubisco, it can be inferred that a reduced quantity of Rubisco protein 
as well as reduced activity of existing enzymes may cause Rubisco activity to decline during flooding. Furthermore, it was reported that phloem transport of photosynthate was blocked and that the demand for sucrose loading was lowered. This may lead to an accumulation of starch in the chloroplasts. ${ }^{13,39}$ It can, thus, be suggested that feedback inhibition of starch accumulation may result in a reduction of CER in flooded plants. The many physiological responses observed indicate that both stomatal and metabolic factors are responsible for the reduction of CER during flooding stress.

\section{Morphological and anatomical modification}

Development of suberized epidermis, arenchyma, hypertrophied lenticels, and adventitious roots waterlogging stress is also known to cause a number of morphological and anatomical changes in plants. For example, the presence of hypertrophied lenticels is a common anatomical change observed in different woody species under flooding stress. ${ }^{54}$ Radical cell division and expansion near stem base results in hypertrophic growth. In addition, it is also believed to be associated with ethylene and auxin production..$^{55}$ The lenticels are thought to be involved in the downward diffusion of $\mathrm{O}_{2}$ as well as, the compounds produced as by-products of anaerobic metabolism (ethanol, $\mathrm{CO}_{2}$ and $\mathrm{CH}_{4}$ ). Although, the actual physiological role of lenticels is still unclear, their presence is often linked to waterlogging tolerance in plants. ${ }^{56}$ Moreover, the number of hypertrophied lenticels is more under the water surface that supports the argument stating their involvement in maintenance of plant water homeostasis and deviating from the argument that dictates their role as important facilitators of oxygen entry toward the root system. Their potential role in the plant water homeostasis is evident from their active involvement in partially replacing the decaying roots and facilitating water intake for the shoot. ${ }^{11}$ Formation of adventitious roots potentially replacing the basal roots is considered as one of the potential morphological adaptations depicted by plants under waterlogging stress. ${ }^{57}$ These specialized roots maintain the continuous supply of water and minerals when the basal root system fails to do so. Furthermore, the deterioration of the main root system is taken as the sacrifice providing energy for the development of well adapted root system. ${ }^{58}$ In addition, the formation of adventitious roots is associated with waterlogging tolerance of plants. ${ }^{59}$ Another important morphological response of plant is the development of lacunae gas spaces (aerenchyma) in the root cortex. The formation of aerenchyma is considered as an adaptive response of the plant under flooding stress. ${ }^{60}$ There are two types of processes involved in the development of aerenchyma. The first is constitutive development of aerenchyma as it is not linked with the abiotic stress. It is formed by the cells separated during tissue development. This type of cell death occurring as a result of cell separation is termed as shizogeny, regulated developmentally and independent of external stimulus. It is formed as a result of highly regulated tissue specific pattern of cell separation. The second type of aerenchyma development is known as Isogeny since it is formed due to partial breakdown of the cortex that resembles programmed cell death and its formation depends on the external stimulus like abiotic stress. ${ }^{61}$ Kramer $^{62}$ reported that tomato plants survive flooding conditions through the production of new adventitious roots. He further stated that the resumption of shoot growth might be attributed to a renewed supply of hormone from the new adventitious roots.

\section{Flooding stress in vegetable crops}

Plant age, time and duration of flooding, condition of the floodwater and site characteristics influence significantly flood tolerance among plant species, genotypes and rootstocks. Flood-tolerant plants endure waterlogging by multifaceted interactions of morphological, anatomical and physiological adaptations. Tolerant genotypes also resist inundation through production of hypertrophied lenticels, aerenchyma tissue and adventitious roots. ${ }^{55}$ In order to increase crop productivity in flooded soils, development of flooding-tolerant lines is required.

Vegetable production occurs in both dry and wet seasons in the tropics. However, production is often limited during the rainy season due to excessive moisture brought about by heavy rain. Most vegetables are highly sensitive to flooding and genetic variation with respect to this character is limited, particularly in tomato. In general, damage to vegetables by flooding is due to the reduction of oxygen in the root zone which inhibits aerobic processes. Flooded tomato plants accumulate endogenous ethylene that causes damage to the plants. ${ }^{63}$ Low oxygen levels stimulate an increased production of an ethylene precursor, 1-aminocyclopropane-1-carboxylic acid (ACC), in the roots. The rapid development of epinastic growth of leaves is a characteristic response of tomatoes to water-logged conditions and the role of ethylene accumulation has been implicated. ${ }^{64}$

Barclay and Crawford ${ }^{65}$ reported that an internal ethanol concentration of $60 \mathrm{~m} \mathrm{~mol} / \mathrm{L}$ appeared to be the threshold value for survival of pea seedlings, and that anoxic death occurred when this concentration was exceeded. To conclude, for poisoning due to excessive accumulation of ethanol to be avoided, it may be important for flooded roots to be able to excrete the ethanol produced by aerobic metabolism. The severity of flooding symptoms increases with rising temperatures; rapid wilting and death of tomato plants is usually observed following a short period of flooding at high temperatures. ${ }^{66}$

Stomatal closure and epinastic curvature take place in some roots and shoots; hence, the effects may involve adjustments to the translocation of hormones or their precursors between the above and below-ground parts. $\mathrm{ABA}$ concentrations were found to increase in roots of pea plants during the $2^{\text {nd }}, 2^{\text {rd }}$ and $4^{\text {th }}$ days of flooding, causing stomata to partially close and enriching the leaves with the hormone. ${ }^{44}$ Neuman et al. ${ }^{67}$ found a doubling of the ABA concentration in the xylem sap of de-topped Phaseolus vulgaris plants after flooding, thus allowing the plants to gain access to the sap which was expressed under pressure. Furthermore, epinastic curvatures can be induced by small amounts of exogenous ethylene and shoots of flooded plants contain increased amounts of endogenously produced gas.$^{68}$ Bradford et al. ${ }^{41}$ also discovered that the ethylene precursor ACC increased in xylem sap of de topped tomato plants after 12 hours of flooding. This suggests that ACC ascends from the roots to the shoots of intact plants.

Flooding stress reduces plant absorption of inorganic nutrients. As a consequence, the adventitious roots of plants can obtain oxygen from air and absorb nutrients; this characteristic may play an important role in its adaptation to flooding conditions. In a study on tomato, Walter et al. ${ }^{69}$ demonstrated that tomato had the most vigorous adventitious root growth compared to cucumber, zucchini and bean. Mano et al., ${ }^{70}$ reported that Dicotyledonous plants (e.g. soybean and tomato) generally form taproot system but develop adventitious roots under flooding conditions. ${ }^{71}$ This characteristic allows the root system to obtain oxygen directly from the air because the adventitious roots formed in the soil and even at the soil surface. The importance of adventitious root formation during flooding has been previously reported for barley ${ }^{72}$ and Italian ryegrass. ${ }^{73}$ 
Remarkably exogenous glucose delayed the onset of ultra structural disintegration in excised pea root cells. ${ }^{74}$ Zhang and Greenway ${ }^{75}$ found that feeding exogenous sugar to beet roots prevented depletion of sugar supplies in the shoots and enhanced ethanolic fermentation. Wample et al. ${ }^{39}$ confirmed that the accumulation of starch in leaves of flooded sunflower plants is a reflection of reduced phloem transport. The results of those studies generally implied that flooding reduces phloem transport and causes further accumulation of photosynthate in leaves and depletion of carbohydrates in roots.

Vartapetian $^{74}$ also reported that upon exposure of detached pea roots to anoxia for more than 9hours periods, there was an irreversible change in the membrane structure and loss of oxidative and phosphorylative activities of mitochondria. Continuous supply of fermentable sugars to roots is considered to be critical for longterm survival of peas, pumpkin and several herbaceous plants under anoxia or flooding. ${ }^{23,43,76}$ In theory, if the translocation path is blocked, assimilates in leaves will not be able to reach the roots, thus resulting in a sugar deficiency in the roots. The sugar level in flooded roots of bitter melon was, however, found to be higher than that in the unflooded control. ${ }^{77}$ Root starch tends to play a role in increasing the level of sugar in the early flooding stage.

Recently, Vincent Ezin et al. ${ }^{78}$ reported that the effect of flooding on two tomato cultivars and two wild related species. Parameters studied include plant height, number of leaves, leaf length, chlorophyll fluorescence, chlorophyll content, wilting, leaf senescence, adventitious root formation, number of flowers and fruits from cluster 2 to 6 , and average weight per fruit, fruit length and width, total fruit weight from cluster 2 to 6 , total yield per plant. LA1579 genotype was more subjected to the deleterious effect of flooding on almost all the parameters studied. Therefore LA1579 genotype is flooding sensitive. Genotypes CLN2498E, and CA4 showed high tolerance to flooding while LA1421 genotype was tolerant to some extent. This information could help in the identification of physiological and agronomical parameters associated with flood-tolerance in vegetables.

Water logging of orchard inhibits flower bud initiation, anthesis, fruit set, fruit size and its quality. If flooding happens during the course of fruit development then some fruits burst or crack. The high internal pressure within the fruit, due to osmotic absorption of water through the root, causes fruit cracking. Fruit cracking in grapes and citrus fruits is a major concern and it badly impairs the quality of the fruit. ${ }^{55}$

\section{Management practices overcome flood damage}

Several management practices have been reported to help crops partially or entirely overcome flood damage. For example, the application of nitrogen $(\mathrm{N})$ fertilizers overcomes $\mathrm{N}$ deficiency, while natural or synthetic hormones are used to correct hormone imbalances and the addition of fungicides help control soil-borne pathogens.

Because of reduced root activity, flooding causes a significant decrease in $\mathrm{N}$ content and the rate of $\mathrm{N}$ accumulation in plants. Plantavailable $\mathrm{N}$ in soils is also very low because of leaching or runoff. Yellowing of leaves due to loss of chlorophyll from leaves within two to three days of waterlogging is probably attributed to $\mathrm{N}$ deficiency. Thus, a strategic use of $\mathrm{N}$ fertilizer after flooding may alleviate $\mathrm{N}$ deficiency and enhance crop recovery from flooding. Growers should apply fertilizers as soon as soils become dry enough for tractor operation. Foliar application of liquid fertilizers is more effective than broadcasting dry fertilizer because of root damage due to flooding. Many kinds of $\mathrm{N}$ fertilizers can be used for crops after flooding.

Recently tested several fertilizers for their effectiveness in recovering flood-damaged vegetable crops and found that potassium nitrate performed the best, urea the second best and calcium nitrate the third. A regular granular dry fertilizer, such as $10 \mathrm{~N}-10 \mathrm{P}_{2} \mathrm{O}_{5}-10 \mathrm{~K} 2 \mathrm{O}$, also can be used for flooded crops, but it is not as effective as foliar and liquid fertilizers.

Various plant growth regulators have been associated with alleviation of waterlogging damages, but there is a dearth of information available on their effects on waterlogged crops. Spraying shoots with a synthetic cytokinin (6-benzylaminopurine [BAP]) has been reported to reduce flooding damage by improvements in leaf extension and retard premature loss of chlorophyll in older leaves. This was related to application of BAP compensating for the restricted transport of natural cytokinin from the root system, affecting metabolism of gibberellins and adversely affecting the inhibitory action of abscisic acid on growth.

Flooding increases the severity of diseases. The symptoms of diseased roots are discoloration, rotting of the root and the premature death of the plant. The damage reduces the ability of the root systems to obtain mineral nutrients or perform other functions essential to the shoot. Two common diseases, Phytophthora and Pythium, cause greatest damage to roots in poorly drained soil. Application of fungicides probably reduces the incidence of disease in waterlogged plants and thereby increases plant tolerance to flooding.

\section{Physiological and molecular approaches to induce waterlogging tolerance}

Scientists from different geographical regions of the world are actively involved in making the plants tolerant to flooding stress by the use of exogenous application of nutrient and plant hormones. For example, recently, Ashraf et al., 5 reported that exogenous application of potassium in soil and as foliar spray alleviated the adverse effects of waterlogging on cotton plants. Likewise, Ashraf et al. ${ }^{79}$ reported that application of nitrate in soil proved useful in mitigating the harmful effects of waterlogging on different physiological attributes of maize. Likewise, Yiu et al., ${ }^{80}$ found that exogenous application of spermidine and spermine provoked several biochemical and physiological adaptations in onion when exposed to flooding stress. Therefore, the use of these organic and inorganic compounds offers an excellent platform for inducing tolerance to flooding stress.

Genetic enhancement using molecular technologies has revolutionized plant breeding. Advances in genetics and genomics have greatly improved our understanding of structural and functional aspects of plant genomes. Combining new knowledge from genomic research with traditional breeding methods enhances our ability to improve vegetable plants. The use of molecular markers as a selection tool provides the potential for increasing the efficiency of breeding programs by reducing environmental variability, facilitating earlier selection and reducing subsequent population sizes for field testing. Molecular markers facilitate efficient introgression of superior alleles from wild species into the breeding programs and enable the pyramiding of genes controlling quantitative traits. Thus, enhancing and accelerating the development of stress tolerant and higher yielding cultivars for farmers in developing countries. Molecular 
marker analysis of stress tolerance in vegetables is limited but efforts are underway to identify QTLs underlying tolerance to stresses. Studies indicate that stress tolerance is quantitatively inherited and in some cases tolerance is dependent on the developmental stage of the plant. Consequently, multiple genes are predicted to be involved with the expression of stress tolerance. This is a critical tool to identify the QTLs underlying tolerance to environmental stresses. Many genes associated with stress tolerance have recently been determined using high throughput expression assays. Integration of QTL analysis with gene discovery and modeling of genetic networks will facilitate a comprehensive understanding of stress tolerance, permit the development of useful and effective markers for marker-assisted selection and identify candidate genes for genetic engineering. Increasing crop productivity in unfavorable environments requires advanced technologies to complement traditional methods which are often unable to prevent yield losses due to environmental stresses. In the past decade, genomics has developed from whole genome sequencing to the discovery of novel and high throughput genetic and molecular technologies. Genes have been discovered and gene functions understood. This has opened the way to genetic manipulation of genes associated with tolerance to environmental stresses. Many activities using these genetic and molecular tools are in place, with some successes. National and international institutes are re-tooling for plant molecular genetics research to enhance traditional plant breeding and benefit from the potential of genetic engineering to increase and sustain vegetable productivity. Vegetable production in the tropics is often limited during the rainy season as most vegetables are highly susceptible to flooding. Genetic variation in this characteristic is limited, particularly in tomatoes, which rapidly wilt and die following a short period of flooding, particularly at high temperatures. ${ }^{66}$ Only limited molecular marker analysis of the characters underlying flooding tolerance in vegetables has been done but work is currently underway at AVRDC-The World Vegetable Center to identify quantitative trait loci (QTLs) underlying tolerance to flooding tolerance in vegetables. The Center is developing easy and reliable screening methods for characterizing new sources of flooding tolerant germplasm from both wild relatives and cultivated lines.

Vegetable production occurs in both dry and wet seasons in the tropics. However, production is often limited during the rainy season due to excessive moisture brought about by heavy rain. Most vegetables are highly sensitive to flooding and genetic variation with respect to this character is limited, particularly in tomato. In general, damage to vegetables by flooding is due to the reduction of oxygen in the root zone which inhibits aerobic processes. Flooded tomato plants accumulate endogenous ethylene that causes damage to the plants. ${ }^{63}$ Low oxygen levels stimulate an increased production of an ethylene precursor, 1-aminocyclopropane-1-carboxylic acid (ACC) in the roots. The rapid development of epinastic growth of leaves is a characteristic response of tomatoes to water-logged conditions and the role of ethylene accumulation has been implicated. ${ }^{64}$ The severity of flooding symptoms increases with rising temperatures; rapid wilting and death of tomato plants is usually observed following a short period of flooding at high temperatures. ${ }^{66}$ Tolerance of crops to flooding is related to many morphological and physiological traits that are under strong environmental influence. ${ }^{81}$ Waterlogging has been a major risk for cucumber production also. The genome of cucumber $(750-1000 \mathrm{~cm})$ is estimated to have seven linkage groups. However different linkages have been observed in several studies. Development of molecular-marker linkage map in many species has facilitated the identification of chromosome regions associated with
Quantitative Trait Loci (QTL). This has provided the opportunity to gain an accurate understanding into traits inheritance and genome organization. Although progress has been made in QTL associated with waterlogging tolerance in other crops such as rice, maize, wheat ${ }^{82}$ and soybean, ${ }^{83}$ little is known about QTL for waterlogging tolerance in cucumber. An indirect selection of waterlogging tolerance using marker assisted selection may prove to be an excellent substitute over traditional phenotypic selection and could improve the efficiency of conventional plant breeding especially as markers are not affected by the environment. Moreover, development of molecular markers for waterlogging tolerance in cucumber would be necessary for future cloning of waterlogging tolerance genes of cucumber. Yeboah et al., ${ }^{84}$ analyzed QTL for waterlogging tolerance of cucumber at the early growth stage, using F23 population from a cross between susceptible and tolerant cucumber lines with the help of ISSR and SRAP markers. In their study a genetic linkage map containing 30 ISSR and 32 SRAPs markers was constructed, spanning a total of $992.2 \mathrm{cM}$ with an average interval of $16.0 \mathrm{cM}$. A total of 25 putative QTL were found to be associated with the six traits studied using Composite Interval Mapping (CIM). The QTL for the waterlogged traits accounted for $7.9-33.2 \%$ of the phenotypic variations while the control traits accounted for $6.9-19.1 \%$ of the phenotypic variations. Although the detected regions need to be mapped precisely, the findings and QTL found in this study could provide useful information for future genetic studies in cucumber flooding tolerance.

It can be inferred from the aforesaid discussion that waterlogging is one of the major constraints for sustainable agriculture. Its effects are evident on the entire plant as well as, cellular levels. There is the need to screen available germplasm for waterlogging tolerance and use the genes responsible for inducing tolerance in other potential crops so as to make them resistant as well. Waterlogging causes deficiency of several essential nutrients. Therefore, exogenous application of these nutrient or other plant hormones could be used so as to alleviate the adverse effects of waterlogging.

\section{Acknowledgements}

None.

\section{Conflict of interest}

The author declares no conflict of interest.

\section{References}

1. Hodgson AS, Chan KY. The effect of short term waterlogging during furrow irrigation of cotton in a cracking grey clay. Austral J Agri Res. 1982;33(1):109-116.

2. Smethurst CF, Garnet T, Shabala S. Nutrition and chlorophyll fluorescence responses of lucerne (Medicago sativa) to waterlogging subsequent recovery. Plant Soil. 2005;270(1-2):31-45.

3. AVRDC. Vegetables Matter. AVRDC - The World Vegetable Center, Shanhua, Taiwan; 2006.

4. Marschner H. Mechanisms of adaptation of plants to acid soils. In: RJ Wright, et al. editors. Plant-soil interactions at low $\mathrm{pH}$. Proceedings of the Second International Symposium on Plant-Soil Interactions at Low pH, 1990, Beckley, West Virginia, USA, Kluwer Aca-demic Publisher; 1991. p. 683-702.

5. Ashraf MA, Ahmad MSA, Ashraf M, et al. Alleviation of waterlogging stress in upland cotton (Gossypium hirsutumL.) by exogenous application of potassium in soil and as a foliar spray. Crop Pasture Sci. 2011;62(1):25-38 
6. Chirkova TV, Zhukova TM, Bugrova MP. Redox reactions of plant cells in response to short-term anaerobiosis. Vestnik SPBGU. 1992;3:82-86.

7. Shewfelt RL, Purvis AC. Lipid peroxidation in plant tissue disorders. Hort Sci. 1995;0(2):213-218.

8. Chang LA, Hammett LK, Pharr DM. Carbon dioxide effects on ethanol production, pyruvate decarboxylase, and alcohol dehydrogenase activities in anaerobic sweet potato roots. Plant Physiol. 1983;71(1):59-62.

9. Touranire-Roux C, Suukta M, Javot H, et al. Cytosolic pH regulated root water transport during anoxic stress through gating of aquaporins. Nature. 2003;425(6956):393-397.

10. Folzer H, Dat J, Capelli N, et al. Response to flooding of sessile oak seedlings (Quercus petraea) to flooding:An integrative study. Tree Physiol. 2006;26(6):759-766.

11. Parent C, Berger A, Folzer H, et al. A novel non symbiotic hemoglobin from oak:cellular and tissue specificity of gene expression. New Phytol. 2008;177(1):142-154.

12. Yordanova R, Christon K, Popova L. Antioxidative enzymes in barley plants subjected to soil flooding. Environ Exp Bot. 2004;51(2):91-101.

13. Liao CT, Lin CH. Effect of flooding stress on photosynthetic activities of Momordica charantia. Plant Physiol Biochem. 1994;32:1-5.

14. Ashraf M, Arfan M. Gas exchange characteristics and water relations in two cultivars of Hibiscus esculentusunder waterlogging. Biol Plant. 2005;49(3):459-462.

15. Carpenter JR, Mitchell CA. Root respiration characteristics of flood-tolerant and intolerant tree species. J Am Soc Hort Sci. 1980;105:684-687.

16. Hsu YM, Tseng MJ, Lin CH. The fluctuation of carbohydrates and nitrogen compounds in flooded wax-apple trees. Bot Bull Acad Sin. 1999;40:193-198.

17. Kuo CC, Chen BW. Physiological responses of tomato cultivars to flooding. J Am Soc Hort Sci. 1980;105:751-755.

18. Lambers H. Respiration and NADH-oxidation of the roots of flood tolerant and flood-intolerant Senecia species as affected by anaerobiosis. Physiol Plant. 1976;37(2):117-122.

19. Lin $\mathrm{CH}$, Lin $\mathrm{CH}$. Physiological adaptation of wax apple to waterlogging. Plant Cell Environ. 1992;15(3):321-328.

20. Liao CT, Lin CH. Effect of flood stress on morphology and anaerobic metabolism of Momordia charantia. Environ Exp Bot. 1995;35(1):105113.

21. Su PH, Lin CH. Metabolic responses of luffa roots to long term flooding. J Plant Physiol. 1996;148(6):735-740.

22. McNamara ST, Mitchell CA. Differential flood stress resistance of two tomato genotypes. J Am Soc Hort Sci. 1989;114(6):976-980.

23. Saglio PH, Raymond P, Pradet A. Metabolic activity and energy charge of excised maize root tips under anoxia. Plant Physiol. 1980;66(6):10531057.

24. Sachs MM, Freeling M, Okimoto R. The anaerobic proteins of maize. Cell. 1980;20(3):761-767.

25. Miernyk JA. Glycolysis, the oxidative pentose phosphate pathway and anaerobic respiration. In: Dennis DT, et al. editors. Plant Physiology, Biochemistry and Molecular Biology. Harlow, UK: Longman; 1990. p. 77-100.

26. Mujer CV, Rumpho ME, Lin JJ, et al. Constitutive and inducible aerobic and anaerobic stress proteins in the Echinochloacomplex and rice. Plant Physiol. 1993;101(1):217-226.
27. Haeberd NP, Edwards KJR. Further studies on the alcohol dehydrogenases in barley:evidence for a third alcohol dehydrogenase locus and data on the effect of an alcohol dehydrogenase-1 null mutation in homozygous and in heterozygous condition. Genet Res Cambridge. 1983;41(2):109-116.

28. Bertani A, Reggiani R. Anaerobic metabolism in rice roots. In: Jackson $\mathrm{MB}$, et al. editors. Plant life under oxygen deprivation, Hague. Netherlands: SPB Academic Publications; 1991. p. 187-199.

29. Miziorko HM, Lorimer GH. Ribulose-1,5-bisphosphate carboxylaseoxygenase. Annu Rev Biochem. 1983;52:507-535.

30. Sage RF, Sharkey TD, Seemann JR. Regulation of ribulose-1,5-bisphosphate carboxylase activity in responses light intensity and $\mathrm{CO}_{2}$ in the C3 annuals Chenopodium albumL. and Phaseolus vulgaris. Plant Physiol. 1990;94(1):1735-1742.

31. Caemmerer SV, Edmondson DL. Relationship between steady-state gas exchange, in vivoribulose bisphosphate carboxylase activity and some carbon reduction cycle intermediates in Raphanus sativus. Aus J Plant Physiol. 1986;13(5):669-688.

32. Sage RF, Sharkey TD, Seemann JR. The in vivoresponse of the ribulose-1,5-bisphosphate carboxylase activation state and the pool sizes of photosynthetic metabolites to elevated $\mathrm{CO}_{2}$ in Phaseolus vulgaris L. Planta. 1988;174(3):407-416.

33. Badger MR, Sharkey TD, von Caemmerer S. The relationship between steady-state gas exchange of bean leaves and the levels of carbon-reduction-cycle intermediates. Planta. 1984;160(4):305-313.

34. Sage RF. A model describing the regulation of ribulose-1,5-bisphosphate carboxylase, electron transport and triose phosphate use in response to light intensity and $\mathrm{CO}_{2}$ in C3 plants. Plant Physiol. 1990;94(4):17281734.

35. Lorimer GH, Badger MR, Andrews TJ. The activation of ribulose-1,5bisphosphate carboxylase by carbon dioxide and magnesium ion. Equilibria, kinetics, a suggested mechanism and physiological implications. Biochem. 1976;15(3):529-536.

36. Bahr JT, Jensen RG. Activation of ribulose bisphosphate carboxylase in intact chloroplasts by $\mathrm{CO}_{2}$ and light. Arch Biochem Biophys. 1978;185(1):39-48.

37. Andrews TJ, Lorimer GH. Rubisco:structure, mechanisms and prospects for improvement. In: Hatch MD, et al. editors. The Biochemistry of Plants. New York, USA: Academic Press; 1987. p. 131-218.

38. Saglio PH. Effect of path or sink anoxia on sugar translocation in roots of maize seedlings. Plant Physiol. 1985;77(2):285-290.

39. Wample RL, Davis RW. Effect of flooding on starch accumulation in chloroplasts of sunflower (Helianthus annuusL.). Plant Physiol. 1983;73(1):195-198.

40. Topa MA, Cheeseman JM. Effects of root hypoxia and a low P supply on relative growth, carbon dioxide exchange rates and carbon partitioning in Pinus serotina seedlings. Physiol Plant. 1992;86(1):136-144.

41. Bradford KJ, Yang SF. Xylem transport of 1-aminocyclopropane- 1carboxylic acid, an ethylene precursor, in waterlogged plants. Plant Physiol. 1980;65(2):322-326.

42. Jackson MB, Kowalewska AKB. Positive and negative messages from roots induce foliar desiccation and stomatal closure in flooded pea plants. J Exp Bot. 1983;34(5):493-506.

43. Jackson MB, Drew MC. Effects of flooding on growth and metabolism of herbaceous plants. In: Kozlowski TT editor. Flooding and Plant Growth. New York, USA: Academic Press; 1984. p. 47-128.

44. Zhang J, Davies WJ. ABA in roots and leaves of flooded pea plants. $J$ Exp Bot. 1987;38(4):649-659. 
45. Jackson MB. Hormones and developmental change in plants subjected to submergence or soil waterlogging. Aquatic Bot. 1990;38(1):49-72.

46. Jackson MB. Regulation of water relationships in flooded plants by ABA from leaves, roots and xylem sap. In: Davies WJ, et al. editors. Abscisic acid:physiology and biochemistry, BIOS Sci. Publlications UK: , Oxford; 1991. p. 217-226.

47. Bradford KJ, Hsiao TC. Stomatal behavior and water relations of waterlogged tomato plants. Plant Physiol. 1982;70(5):1508-1513.

48. Liao CT, Lin CH. Photosynthetic responses of grafted bitter melon seedlings to flooding stress. Environ Exp Bot. 1996;36(2):167-172.

49. Smith MW, Ager PL. Effect of soil flooding on leaf gas exchange of seedling pecan trees. Hort Sci. 1988;23(2):370-372.

50. Vu CV, Yelenosky G. Photosynthetic responses of citrus trees to soil flooding. Physiol Plant. 1991;81(1):7-14.

51. Davies FS, Flore JA. Short-term flooding effects on gas exchange and quantum yield of rabbiteye blueberry (Vaccinium asheiReade). Plant Physiol. 1986;81(1):289-292.

52. Davies FS, Flore JA. Gas exchange and flooding stress of high bush and rabbiteye blueberries. J Am Soc Hort Sci. 1986;111:565-571.

53. Andrews TJ, Lorimer GH. Rubisco:structure, mechanisms and prospects for improvement. In: Hatch MD, et al. editors. The Biochemistry of Plants. New York, USA: Academic Press; 1986. p. 131-218.

54. Yamamoto F, Sakata T, Terazawa K. Physiological, morphological and anatomical response of Fraxin mandshurica seedlings to flooding. Tree Physiol. 1995;15(11):713-719.

55. Kozlowski TT. Responses to woody plants to flooding and salinity. Tree physiology, Monograph No. 1, Victoria, Canada: Heron Publishing; 1997. p. 29

56. Parelle J, Brendel O, Bodenes C, et al. Differences in morphologica and physiological responses to waterlogging between two sympatric oak species (Quercus petraea[Matt.] Liebl., Quercus roburL.). Ann Forest Sci. 2006;63(8):849-859.

57. Malik AI, Colmer TD, Lamber H, et al. Changes in physiological and morphological traits of roots and shoots of wheat in response to different depths of waterlogging. Aust J Plant Physiol. 2001;28(11):1121-1131.

58. Dat J, Folzer H, Parent C, et al. Hypoxia stress:current understanding and perspectives. In: Teixeira da Silva JA editor. Floriculture, ornamental and plant biotechnology. Advances and tropical issues (Volume 3), Global Science books, Isleworth, United Kingdom; 2006. p. 664-674.

59. Steffens B, Wang J, Santer M. Interactions between ethylene, gibberellins and abscisic acid regulate emergence and growth rate of adventitious roots in deep water rice. Planta. 2006;223(3):604-612.

60. Evans DE. Aerenchyma formation. New phytol. 2003;161:35-49.

61. Pellinen R, Palva T, Kangasjarvi J. Subcellular localization of ozoninduced hydrogen peroxide production in birch (Betula pendula) leaf cells. Plant J. 1999;20(3):349-356.

62. Kramer PJ. Causes injury to plants resulting from flooding of the soil. Plant Physiol. 1951;26(4):722-736.

63. Drew MC. Plant responses to anaerobic conditions in soil and solution culture. Cur Adv Plant Sci. 1979;36:1-14.

64. Kawase M. Anatomical and morphological adaptation of plants to waterlogging. Hort Sci. 1981;16:30-34.

65. Barclay AM, Crawford RMM. Temperature and anoxic injury in pea seedlings. J Exp Bot. 1981;32(5):943-949.
66. Kuo DG, Tsay JS, Chen BW, et al. Screening for flooding tolerance in the genus Lycopersicon. Hort Sci. 1982;17(1):76-78.

67. Neuman DS, Smit B. The influence of leaf water status and ABA on leaf growth and stomata of Phaseolus seedlings with hypoxic roots. $J$ Exp Bot. 1991;42(12):1499-1506.

68. Jackson MB, Campbell DJ. Waterlogging and petiole epinasty in tomato:the role of ethylene and low oxygen. New Phytol. 1976;76(1):21-29.

69. Walter S, Heuberger H, Schnitzler WS. Sensibility of different vegetables of oxygen deficiency and aeration with $\mathrm{H}_{2} \mathrm{O}_{2}$ in the rhizosphere. Acta Horticulturae. 2004;659(66):499-508.

70. Mano Y, Omori F. Breeding for flooding tolerant maize using "teosinte" as a germplasm resource. Plant Root. 2007;1:17-21.

71. Bacanamwo M, Purcell LC. Soybean root morphological and anatomical traits associated with acclimation to flooding. Crop Sci. 1999;39(1):143-149.

72. Stanca AM, Romagosa I, Takeda K, et al. Diversity in abiotic stress tolerances. In: von Bothmer R, et al. editors. Diversity in Barley (Hordeum vulgare). Amsterdam: Elsevier Science BV; 2003. p. 1-280.

73. Tase K, Kobayasi M. Studies on flooding tolerance in Italian ryegrass 2. Simple screening technique for flooding tolerance in Italian ryegrass. Hokuriku Sakumotsu Gak-kaiho. 1992;27:76-78

74. Vartapetian BB. Flood-sensitive plants under primary and secondary anoxia:ultrastructural and metabolic responses. In: Jackson MB, et a editors. Plant life under oxygen deprivation:ecology, physiology and biochemistry. Hague, Netherlands: SPB Acadmeic Publications; 1991. p. 201-216.

75. Zhang Q, Greenway H. Anoxia tolerance and anaerobic catabolism of aged beet root storage tissues. $J$ Exp Bot. 1994;45(5):567-575.

76. Webb T, Armstrong W. The effects of anoxia and carbohydrates on the growth and viability of rice, pea and pumpkin roots. $J$ Exp Bot. 1983;34(5):579-603.

77. Su PH, Wu TH, Lin CH. Root sugar level in flooded luffa and bitter melon is not referential to flooding tolerance. Bot Bull Acad Sin 1998;39:175-179.

78. Vincent Ezin, Robert De La Pena, et al. Flooding tolerance of tomato genotypes during vegetative and reproductive stages. Braz J Plant Physiol. 2010;22(2):131-142

79. Ashraf M, Rehman H. Mineral nutrient status of corn in relation to nitrate and long term waterlogging. J Plant Nutr. 1999;22(8):1253-1268.

80. Yiu JC, Liu CW, Fang DYT, et al. Waterlogging tolerance of Welsh onion (Allium fistulosum L.) enhanced by exogenous spermidine and spermine. Plant Physiol Biochem. 2009;47(8):710-716.

81. Kozlowski TT. Extent, causes, and impact of flooding. In Kozlowski TT. Flooding and plant growth. New York: Academic Press; 1984. p. 1-7.

82. Boru G, van Ginkel M, Kronstad WE, et al. Expression and inheritance of tolerance to waterlogging stress in wheat. Euphytica. 2001;117(2):9198.

83. Reyna N, Cornelious B, Shannon JG, et al. Evaluation of a QTL for waterlogging tolerance in southern soybean germplasm. Crop Sci. 2003;43(6):2077-2082.

84. Yeboah MA, Xuehao C, Feng CR, et al. Mapping quantitative trait loci for waterlogging tolerance in cucumber using SRAP and ISSR markers. Biotech. 2008;7(2):157-167. 